\title{
Catalysis

\section{Development of a post-synthetic method for tuning the Al content of OSDA-free Beta as a catalyst for conversion of methanol to olefins $\dagger$}

Cite this: Catal. Sci. Technol., 2016, 6,713

\author{
Ryoichi Otomo, ${ }^{a}$ Ulrich Müller, ${ }^{\mathrm{b}}$ Mathias Feyen, ${ }^{\mathrm{b}}$ Bilge Yilmaz, ${ }^{\mathrm{c}}$ Xiangju Meng, ${ }^{\mathrm{d}}$ \\ Feng-Shou Xiao, ${ }^{d}$ Hermann Gies, ${ }^{e}$ Xinhe Bao, ${ }^{f}$ Weiping Zhang, ${ }^{9}$ Dirk De Vos ${ }^{h}$ and \\ Toshiyuki Yokoi*a
}

\begin{abstract}
Zeolites synthesized without any organic structure-directing agent (OSDA) have several advantages over conventional zeolites synthesized with OSDAs. Their Al-rich compositions, however, are sometimes not suitable for applications as catalysts. In the present study, post-synthetic modification was performed using an Al-rich Beta zeolite synthesized without any OSDAs (designated as "Beta(OF)") to obtain high-silica Beta zeolites. We have successfully developed a facile post-synthetic method for tuning the Al content of Beta(OF) with the ${ }^{*}$ BEA-type structure retained by calcination at $>750{ }^{\circ} \mathrm{C}$ followed by acid treatment. Solid-state ${ }^{29} \mathrm{Si}$ and ${ }^{27} \mathrm{Al}$ MAS NMR analyses revealed that during calcination, framework Al atoms were isomorphously substituted with Si atoms to form high-silica frameworks and concomitant extra-framework Al species. The stability of the obtained frameworks against acid treatment was evaluated in terms of the framework Al content, finding that the framework with the Si/Al ratio higher than 12 is well stabilized enough for acid treatment. Thus, dealuminated Beta(OF) zeolites with high-silica compositions were found to be effective catalysts for the methanol-to-olefin (MTO) reaction; particularly, the Beta zeolite with the $\mathrm{Si} / \mathrm{Al}$ ratio of 112 maintained the conversion of methanol over $90 \%$ with selectivity to $\mathrm{C}_{2}-\mathrm{C}_{4}$ olefins over $70 \%$ even at 40 hours on stream at WHSV $=3.2 \mathrm{~h}^{-1}$.
\end{abstract}

Received 24th June 2015,

Accepted 19th August 2015

DOI: $10.1039 /$ c5cy00944h

www.rsc.org/catalysis of OSDAs releases $\mathrm{CO}_{2}$ and $\mathrm{NO}_{x}{ }^{4,5}$ Recently, it has been reported that several types of zeolites, which were conventionally synthesized with particular OSDAs, can be synthesized without any OSDA, so-called "organotemplate-free" or "OSDAfree" synthesis. An outstanding example is the OSDA-free synthesis of Beta zeolite. ${ }^{6}$

Beta zeolite, with a three-dimensional 12-membered ring pore system, has been widely investigated and used in scientific and industrial fields as a catalyst for the synthesis of petrochemical and fine chemical products such as hydrocracking of paraffins ${ }^{7,8}$ and Friedel-Crafts reactions of aromatic compounds. $^{9-11}$ Beta zeolite shows unique shape selectivities in the rearrangement of allyl benzyl ethers, ${ }^{12}$ Diels-Alder reaction, ${ }^{13}$ and Meerwein-Ponndorf-Verley reduction. ${ }^{14}$ Furthermore, increasing attention has recently been paid to its application as a catalyst for $\mathrm{NO}_{x}$ decomposition in automobile exhaust gas. ${ }^{15,16}$

The synthesis of Beta zeolite was first achieved by Wadlinger et al. using the tetraethylammonium (TEA) cation as an OSDA. ${ }^{17}$ Since the first report, Beta zeolites have been synthesized by a variety of methods typically using the TEA cation. ${ }^{18-20}$ In 2007 , Xiao et al. first reported the OSDA-free synthesis of Beta zeolite, which is designated as "Beta(OF)". 6 Later, following this report, successful examples have also 
been reported by other groups. ${ }^{21-24}$ Thus, the synthesized Beta zeolites were highly crystalline materials and their $\mathrm{Si} / \mathrm{Al}$ ratios ranged from 4 to 6 , which are much lower than those of the conventional Beta zeolites synthesized with TEA cations.

There are several reports on the catalytic applications of Beta(OF). ${ }^{25-30}$ Taking advantage of the large cation-exchange capacity, Fe-exchanged Beta(OF) was applied in $\mathrm{NO}_{x}$ decomposition. $^{25,26}$ Beta(OF) with a large number of Brønsted acid sites showed high catalytic activities in cracking of cumene and Friedel-Crafts reactions. ${ }^{27,28}$ In contrast, it has been reported that the high $\mathrm{Al}$ content resulted in fast deactivation and that the appropriate dealumination providing $\operatorname{Beta}(\mathrm{OF})$ with high-silica compositions delayed the deactivation. ${ }^{29,30}$ According to these reports, OSDA-free Beta with high Al content is fragile under acidic conditions and stabilization of the framework by steam treatment is indispensable for obtaining high-silica Beta(OF). However, to our best knowledge, the quantitative evaluation of such stabilization of Beta(OF) has not been reported, though it is essential for establishing a general and reproducible modification method.

Recently, the global demand for light olefins has been increasing and the balance between the demand and the supply has become tight (further tightening in the future is expected). ${ }^{31,32}$ Methanol-to-olefin (MTO) reaction is a versatile process for producing light olefins from methanol, which can be obtained from various resources including coal, natural gas, shale gas and biomass. ${ }^{33-35}$ SAPO-34 as a typical catalyst exhibited remarkably high selectivity to olefins; the combined selectivity to ethene and propene exceeds $80 \% .^{36}$ Nowadays, the widening diversity of chemical industries requires a variety of raw materials, in which butenes as well as ethene and propene have been in great demand. Since medium- and small-pore zeolites do not meet this demand, we have adopted aluminosilicate zeolites having large pores, i.e., Beta zeolites as catalysts for the MTO reaction.

Here, a facile post-synthetic method for tuning the Al content of $\operatorname{Beta}(\mathrm{OF})$ with the *BEA-type structure retained has been developed based on calcination at $>750{ }^{\circ} \mathrm{C}$ followed by acid treatment. We evaluated quantitatively the degree of framework stabilization in terms of the framework Al content. Thus, the prepared zeolites were used in the conversion of methanol by virtue of the high-silica compositions.

\section{Experimental}

\section{Synthesis and modification of Beta(OF) zeolite}

The parent Beta(OF) was synthesized following the method reported by Xiao et al. ${ }^{6,24}$ The obtained Na-form sample, designated as Beta(OF)-as, was stirred in $2.5 \mathrm{~mol} \mathrm{l}^{-1}$ ammonium nitrate solution at $80^{\circ} \mathrm{C}$ for $2 \mathrm{~h}$ and dried at $100{ }^{\circ} \mathrm{C}$. This treatment was repeated two times to obtain the ammoniumform sample free of sodium, and thus the prepared product is denoted as Beta(OF)- $\mathrm{NH}_{4}$.

$\operatorname{Beta}(\mathrm{OF})-\mathrm{NH}_{4}$ was calcined in air under different conditions $\left(650-800{ }^{\circ} \mathrm{C}\right.$ and $\left.5-24 \mathrm{~h}\right)$ in a muffle furnace. The calcined samples are designated as Cal $x-y \mathrm{~h}$, where $x$ and $y$ are the temperature and the period of calcination, respectively. Acid treatment of the calcined samples was performed by stirring a mixture consisting of the sample powder $(2 \mathrm{~g})$ and nitric acid solution $(100 \mathrm{ml})$ in a glass flask at ambient temperature. The solid sample was recovered by filtration, thoroughly washed with water, and dried at $100{ }^{\circ} \mathrm{C}$. Thus, the obtained sample is designated as "Cal $x-y \mathrm{~h}-X \mathrm{M}-\mathrm{Amb}-Y \mathrm{~h}$ ", where $X$ and $Y$ are the concentration of nitric acid $\left(\mathrm{mol} \mathrm{l}^{-1}\right)$ and the period of treatment, respectively. "Amb" means the treatment at ambient temperature and when acid treatment was performed under reflux, the sample is designated with "Ref" instead of "Amb".

\section{Characterization of Beta(OF) zeolite}

Powder X-ray diffraction (XRD) patterns were collected on a Rigaku Ultima III diffractometer using $\mathrm{Cu} \mathrm{K \alpha}$ radiation (40 $\mathrm{kV}, 40 \mathrm{~mA}$ ). The chemical compositions of the solid samples were analyzed with a Shimadzu ICPE-9000 analyzer. Solidstate ${ }^{29}$ Si MAS NMR spectra were measured on a JEOL ECA400 spectrometer at a resonance frequency of 79.5 $\mathrm{MHz}$ using a $6 \mathrm{~mm}$ sample rotor at a spinning rate of $5.5 \mathrm{kHz}$. Solidstate ${ }^{27} \mathrm{Al}$ MAS NMR spectra were measured on a JEOL ECA600 spectrometer at a resonance frequency of $156.4 \mathrm{MHz}$ using a $4 \mathrm{~mm}$ sample rotor at a spinning rate of $15.0 \mathrm{kHz}$. Nitrogen adsorption-desorption measurements were conducted using a BELSORP-mini analyzer (MicrotracBEL) at $-196{ }^{\circ} \mathrm{C}$ and the BET surface area was calculated in the $P / P_{0}$ range of $0-0.1$. The acid amount was determined by temperature-programmed desorption (TPD) of $\mathrm{NH}_{3}$ using a BELCAT (MicrotracBEL) with a thermal conductivity detector.

\section{Catalytic tests}

Conversion of methanol was performed in a fixed-bed flow reactor with a quartz tube. The catalyst powder was compressed into wafers, crushed and sieved to obtain $0.5-1 \mathrm{~mm}$ particles. Thus, the obtained particles $(0.1 \mathrm{~g})$ were set in the quartz tube by filling the top and the bottom of the catalyst bed with quartz wool. The reaction temperature was measured using a thermocouple inserted into the catalyst bed. The catalyst was activated at $500{ }^{\circ} \mathrm{C}$ for $1 \mathrm{~h}$ in helium flow. Methanol was vaporized in dry helium and fed to the reactor kept at $500{ }^{\circ} \mathrm{C}$. The partial pressure of methanol $\left(P_{\mathrm{MeOH}}\right)$ was controlled by adjusting the helium flow rate with the methanol feed rate constant, giving $P_{\mathrm{MeOH}}$ values of 50 and $75 \mathrm{kPa}$. The reactor effluent was analyzed by using an on-line GC-FID (GC-2014, Shimadzu) equipped with an HP-PLOT Q column (Agilent J\&W). The selectivities to each product are expressed in carbon percentage.

\section{Results and discussion}

\section{Synthesis and ion exchange of $\operatorname{Beta}(\mathrm{OF})$ zeolite}

Beta(OF)-as showed a typical XRD pattern assigned to a *BEAtype structure that consists of polymorphs $\mathrm{A}$ and $\mathrm{B}$ with 
stacking disorder, which is also observed in the conventional Beta zeolite synthesized with the TEA cation and natural zeolite Tschernichite. ${ }^{37-39}$ Notably, a trace amount of MOR phase was also found as contamination. The crystalline structure did not change after ion exchange to the ammonium form (Fig. 1). The Si/Al ratios of Beta(OF)-as and Beta(OF)- $\mathrm{NH}_{4}$ were 4.4 and 4.6, respectively, which were very low compared to that of the conventional Beta zeolite which has typically a value of 12 (Table 1). Fig. 2 shows the ${ }^{27} \mathrm{Al}$ MAS and ${ }^{29} \mathrm{Si}$ MAS NMR spectra before and after ion exchange. In the ${ }^{27} \mathrm{Al}$ NMR spectra, Beta(OF)-as showed an intense peak at $57 \mathrm{ppm}$ with a shoulder peak at $54 \mathrm{ppm}$. These two peaks are assigned to tetrahedral Al atoms at T3-T9 sites and those at T1 and T2 sites in the * BEA-type framework, respectively. ${ }^{40}$ The absence of a peak at around $0 \mathrm{ppm}$ indicated that Beta(OF)-as had no Al species in octahedral coordination. Two similar slightly sharpened peaks were seen in the spectrum of Beta(OF)- $\mathrm{NH}_{4}$, indicating no change in the coordination of $\mathrm{Al}$ atoms during the ion exchange.

Beta(OF)-as and Beta(OF)- $\mathrm{NH}_{4}$ showed similar ${ }^{29} \mathrm{Si}$ NMR spectra consisting of four distinct peaks. The peaks at -113 and $-108 \mathrm{ppm}$ are assigned to $\mathrm{Q}^{4}$ (4-OSi, at $\mathrm{T} 1$ and $\mathrm{T} 2$ sites) and $\mathrm{Q}^{4}$ (4-OSi, at T3-T9 sites) species, respectively, where $\mathrm{Q}^{n}$ is $\mathrm{Si}(\mathrm{OM})_{n}(\mathrm{OH})_{4-n}$ species $(\mathrm{M}=\mathrm{Si}$ or $\mathrm{Al}) \cdot \mathrm{Q}^{4}$ (3-OSi, 1-OAl) and $\mathrm{Q}^{3}$ (3-OSi, 1-OH) species overlapped each other, constituting the peak at $-102 \mathrm{ppm}$. The peak at $-97 \mathrm{ppm}$ is assigned to $\mathrm{Q}^{4}$ (2-OSi, 2-OAl) species. ${ }^{24,28,40,41}{ }^{29} \mathrm{Si} \mathrm{NMR}$ analysis indicates that the structure and composition of the framework were intact after the ion exchange.

\section{Calcination of Beta(OF)- $\mathrm{NH}_{4}$}

The XRD patterns of Beta(OF) samples before and after calcination are shown in Fig. 3. Although calcination at high temperatures resulted in a slight decrease in the diffraction intensities, the crystalline structure was definitely retained after calcination. For Beta(OF)- $\mathrm{NH}_{4}$, the most intense diffraction peak appeared at $22.1^{\circ}$, which was shifted to a high angle up to $22.5^{\circ}$ for Cal800-24h (Fig. S1 $\dagger$ ). This behavior was related to shrinkage of the framework, as discussed below.

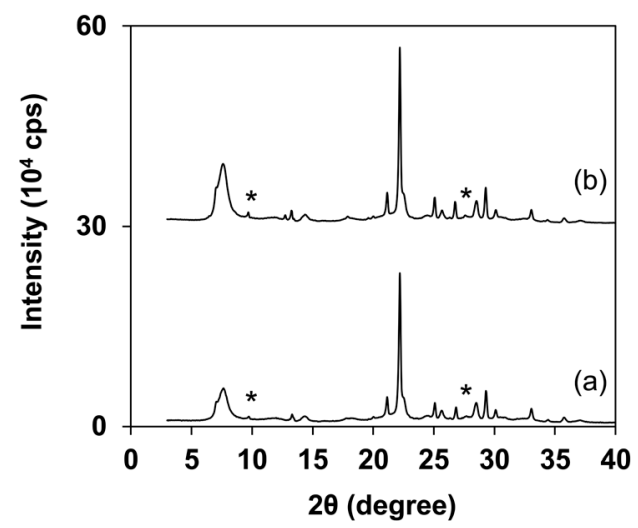

Fig. 1 XRD patterns of (a) Beta(OF)-as and (b) Beta(OF)- $\mathrm{NH}_{4}$. The asterisk indicates the MOR phase.
Table 1 Compositional and textural properties of Beta(OF) zeolites

\begin{tabular}{lll}
\hline Sample & $\mathrm{Si} / \mathrm{Al}^{a}$ & $S_{\text {BET }}{ }^{b}\left(\mathrm{~m}^{2} \mathrm{~g}^{-1}\right)$ \\
\hline Beta(OF)-as & 4.4 & 677 \\
Beta(OF)-NH & - \\
Cal650-5h & 4.6 & 641 \\
Cal700-5h & 4.5 & 660 \\
Cal750-5h & 4.5 & 644 \\
Cal750-15h & 4.5 & 604 \\
Cal800-24h & 4.5 & 559
\end{tabular}

${ }^{a}$ The whole $\mathrm{Si} / \mathrm{Al}$ ratio analysed by ICP. ${ }^{b}$ BET surface area calculated from $\mathrm{N}_{2}$ adsorption isotherms.

${ }^{27} \mathrm{Al}$ MAS NMR analysis shows several changes in the local structure of the Al species induced by autosteaming during calcination (Fig. 4). Cal650 showed two peaks at 54 and 57 ppm with a remarkable decrease in the peak at 57 ppm compared to $\mathrm{Beta}(\mathrm{OF})-\mathrm{NH}_{4}$, indicating that the framework $\mathrm{Al}$ atoms at T3-T9 sites were preferentially converted into extraframework $\mathrm{Al}$ species. ${ }^{42}$ Broad peaks at $0-10 \mathrm{ppm}$ are assigned to extra-framework $\mathrm{Al}$ species in octahedral coordination. Severe calcination above $700{ }^{\circ} \mathrm{C}$ led to further decrease in the peaks of the framework $\mathrm{Al}$ atoms and various types of extra-framework $\mathrm{Al}$ species were generated; for example, four- and five-coordinated extra-framework Al species appeared with broad peaks at $\sim 60$ and $\sim 30 \mathrm{ppm}$, respectively. $^{42-45}$ These species were slightly or hardly observed in the conventional Beta zeolites after severe calcination or steam treatment. ${ }^{46-48}$ For OSDA-free Beta with a high $\mathrm{Al}$ content, a large number of the Al atoms could diversify the extra-framework $\mathrm{Al}$ species. Note that extra-framework $\mathrm{Al}$ species in an asymmetric local environment are less sensitive to NMR analysis because of strong quadrupolar interaction and so the total intensity decreased as the calcination temperature increased.

By observing the ${ }^{29} \mathrm{Si}$ MAS NMR spectra of the calcined products (Fig. 5), we found that the coordination environment of Si atoms was also changed during calcination. For the calcined samples, the peaks attributed to $\mathrm{Q}^{4}(1 \mathrm{Al})+\mathrm{Q}^{3}$, $\mathrm{Q}^{4}$ (0Al, T3-T9), and $\mathrm{Q}^{4}$ (0Al, T1 and T2) appeared at -104,
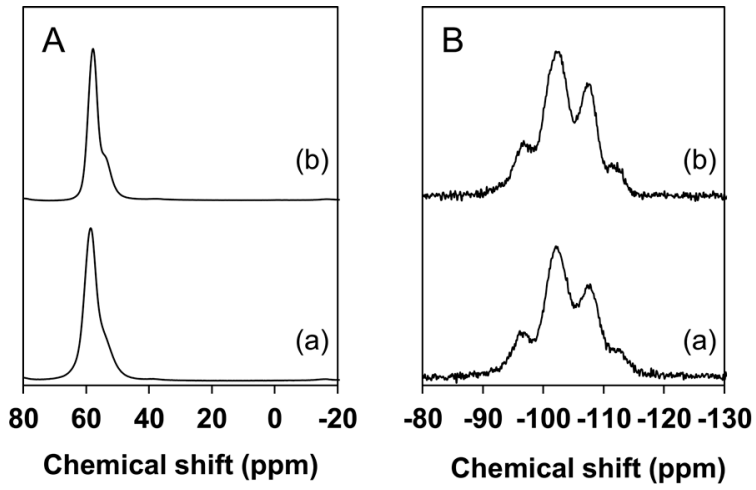

Fig. 2 (A) ${ }^{27} \mathrm{Al}$ MAS and (B) ${ }^{29} \mathrm{Si}$ MAS NMR spectra of (a) Beta(OF)-as and (b) Beta(OF)- $\mathrm{NH}_{4}$. 


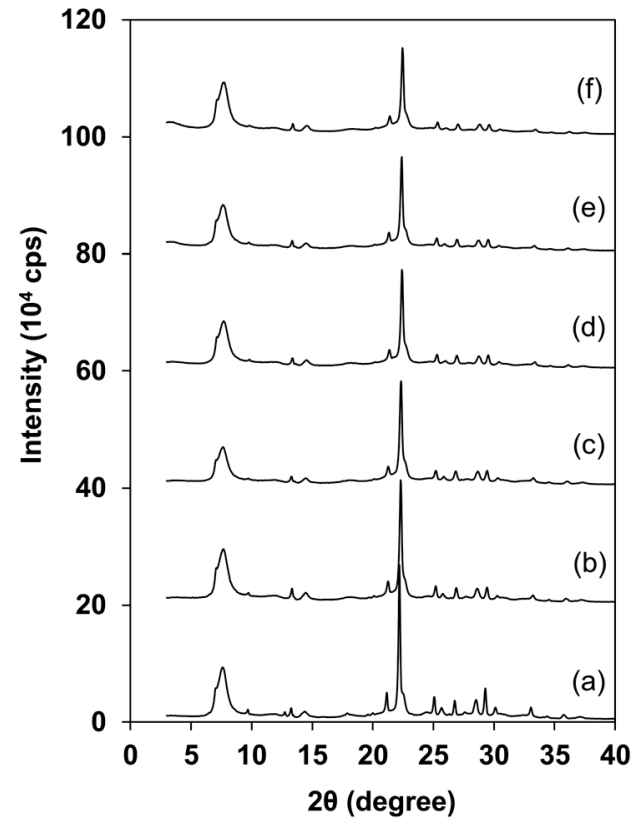

Fig. 3 XRD patterns of Beta(OF) zeolites before and after calcination: (a) Beta(OF)- $\mathrm{NH}_{4}$, (b) Cal650-5h, (c) Cal700-5h, (d) Cal750-5h, (e) Cal750-15h, and (f) Cal800-24h

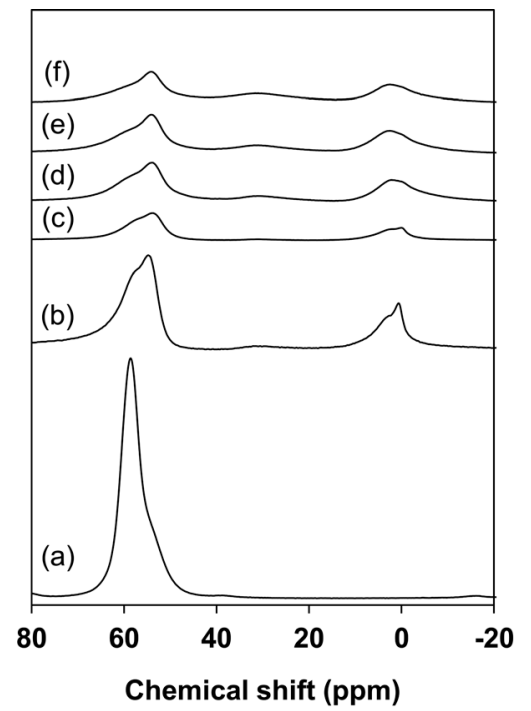

Fig. $4{ }^{27} \mathrm{Al}$ MAS NMR spectra of Beta(OF) zeolites before and after calcination: (a) Beta(OF)- $\mathrm{NH}_{4}$, (b) Cal650-5h, (c) Cal700-5h, (d) Cal750$5 \mathrm{~h}$, (e) Cal750-15h, and (f) Cal800-24h.

-110, and $-114 \mathrm{ppm}$, respectively. These peaks were shifted from $-102,-108$, and -112 ppm, respectively, for Beta(OF)$\mathrm{NH}_{4}$. In order to quantitatively evaluate the changes, all the spectra were deconvoluted and fitted with Gaussian functions; the relative peak areas in percent are listed in Table 2. After calcination at $650{ }^{\circ} \mathrm{C}$, the proportions of $\mathrm{Q}^{4}(2 \mathrm{Al})$ and $\mathrm{Q}^{4}(1 \mathrm{Al})+\mathrm{Q}^{3}$ species decreased from 13 and $55 \%$ to 9 and $35 \%$, respectively. Cleavage of a $\mathrm{Si}-\mathrm{O}-\mathrm{Al}$ bond is accompanied by the formation of a silanol group and the total

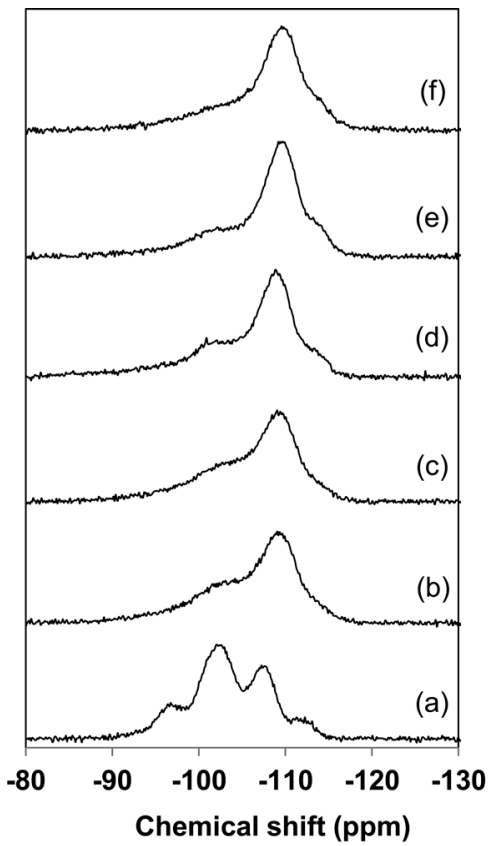

Fig. $5{ }^{29} \mathrm{Si}$ MAS NMR spectra of Beta(OF) zeolites before and after calcination: (a) Beta(OF)- $\mathrm{NH}_{4}$, (b) Cal650-5h, (c) Cal700-5h, (d) Cal7505h, (e) Cal750-15h, and (f) Cal800-24h.

number of $\mathrm{Q}^{4}(1 \mathrm{Al})$ and $\mathrm{Q}^{3}$ species would not be changed. The decrease in these peaks, however, was definitely observed and the proportion of $\mathrm{Q}^{4}$ species, especially $\mathrm{Q}^{4}$ (0Al, T3-T9) species, increased from 27 to $52 \%$. These results imply that the condensation of the resulting silanol groups simultaneously occurred. The changes in the proportion of Si species were remarkably observed in the samples calcined under severer conditions; for Beta(OF)-Cal800-24h, the proportions of $\mathrm{Q}^{4}(2 \mathrm{Al})$ and $\mathrm{Q}^{4}(1 \mathrm{Al})+\mathrm{Q}^{3}$ species decreased to 4 and $24 \%$, respectively, with an increase in the proportion of $\mathrm{Q}^{4}(0 \mathrm{Al}$, T3-T9) and $\mathrm{Q}^{4}(0 \mathrm{Al}, \mathrm{T} 1$ and $\mathrm{T} 2)$ species to 62 and $10 \%$, respectively. A similar behavior was observed in the steaming of the Beta zeolites synthesized by the OSDA-free method. ${ }^{30}$

The framework $\mathrm{Si} / \mathrm{Al}$ ratios, abbreviated as $\mathrm{Si} / \mathrm{Al}_{\mathrm{FW}}$ ratios, were calculated based on the proportion of Si species analyzed by ${ }^{29} \mathrm{Si}$ NMR according to the following equation, where $A_{\mathrm{Si}(m \mathrm{Al})}$ is the peak area of $(\mathrm{OAl})_{m} \mathrm{Si}(\mathrm{OSi} \text { or } \mathrm{OH})_{4-m}$ species (Table 2).

$$
\mathrm{Si} / \mathrm{Al}_{\mathrm{FW}}=\sum_{n=0}^{4} A_{\mathrm{Si}(m \mathrm{Al})} / \sum_{n=0}^{4} \frac{n}{4} A_{\mathrm{Si}(m \mathrm{Al})}
$$

The $\mathrm{Si} / \mathrm{Al}_{\mathrm{FW}}$ ratio of $\mathrm{Beta}(\mathrm{OF})-\mathrm{NH}_{4}$ was 4.9 , which was very similar to the whole $\mathrm{Si} / \mathrm{Al}$ ratio calculated by ICP analysis. The $\mathrm{Si} / \mathrm{Al}_{\mathrm{FW}}$ ratios increased along with the severity of calcination up to 12.5 for Cal800-24h. The formation of siliceous frameworks was also supported by the peak shift to a high angle in the XRD analysis (Fig. 3).

Thus, the ${ }^{27} \mathrm{Al}$ and ${ }^{29} \mathrm{Si} \mathrm{NMR}$ analyses clarified the structural changes during calcination; the $\mathrm{Si}-\mathrm{O}-\mathrm{Al}$ bonds surrounding an $\mathrm{Al}$ atom were hydrolyzed to form extra- 
Table 2 Relative ${ }^{29}$ Si NMR peak area, framework Al content, and stability against acid treatment of Beta(OF) zeolites

\begin{tabular}{|c|c|c|c|c|c|c|}
\hline Sample & $\mathrm{Q}^{4}(2 \mathrm{Al})(\%)$ & $\mathrm{Q}^{4}(1 \mathrm{Al})+\mathrm{Q}^{3}(\%)$ & $\mathrm{Q}^{4}(0 \mathrm{Al}, \mathrm{T} 3-\mathrm{T} 9)(\%)$ & $\mathrm{Q}^{4}(0 \mathrm{Al}, \mathrm{T} 1$ and $\mathrm{T} 2)(\%)$ & $\mathrm{Si} / \mathrm{Al}_{\mathrm{FW}}{ }^{a}$ & Stability $^{b}$ \\
\hline $\operatorname{Beta}(\mathrm{OF})-\mathrm{NH}_{4}$ & 13 & 55 & 27 & 5 & 4.9 & - \\
\hline Cal650-5h & 9 & 35 & 52 & 4 & 7.7 & Collapsed \\
\hline Cal700-5h & 8 & 36 & 49 & 7 & 7.7 & Collapsed \\
\hline Cal750-5h & 7 & 30 & 56 & 7 & 8.3 & Partly collapsed \\
\hline Cal750-15h & 4 & 25 & 63 & 8 & 12.1 & Retained \\
\hline Cal800-24h & 4 & 24 & 62 & 10 & 12.5 & Retained \\
\hline
\end{tabular}

framework Al species and simultaneously, the resulting defects were mended by their condensation, leading to reconstruction of $\mathrm{Si}-\mathrm{O}-\mathrm{Si}$ bonds. As a whole, some of the tetrahedral $\mathrm{Al}$ atoms in the framework were isomorphously substituted with $\mathrm{Si}$ atoms, resulting in the formation of siliceous framework and extra-framework Al species. Interestingly, the number of Si atoms at the T3-T9 sites preferentially increased after calcination, corresponding to the findings that a major fraction of $\mathrm{Al}$ atoms originally occupied these sites in $\mathrm{Beta}(\mathrm{OF})-\mathrm{NH}_{4}$ and that the $\mathrm{Al}$ atoms at these sites were more easily hydrolyzed than those at the T1 and T2 sites.

\section{Acid treatment of calcined Beta(OF) zeolites}

The calcined samples were treated with $1 \mathrm{~mol} \mathrm{l}^{-1}$ nitric acid solution at ambient temperature for 24 hours; the changes in the crystalline structures after acid treatment were investigated (Fig. 6). Significant collapse of the framework was observed after the treatment of Cal650-5h-1M-Amb-24h and Cal700-5h-1M-Amb-24h. Although the framework structure of Cal750-5h-1M-Amb-24h partly collapsed, those of Cal750-15h$1 \mathrm{M}-\mathrm{Amb}-24 \mathrm{~h}$ and Cal800-24h-1M-Amb-24h were successfully retained.

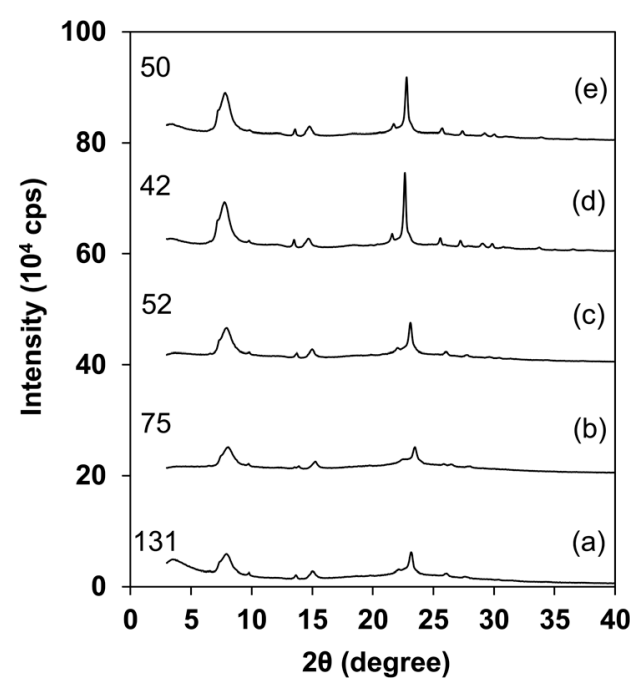

Fig. 6 XRD patterns of calcined and acid-treated Beta(OF) zeolites: (a) Cal650-5h-1M-Amb-24h, (b) Cal700-5h-1M-Amb-24h, (c) Cal750-5h1M-Amb-24h, (d) Cal750-15h-1M-Amb-24h, and (e) Cal800-24h-1M$\mathrm{Amb}-24 \mathrm{~h}$. The numbers inside the graph are their Si/Al ratios.
The ${ }^{29} \mathrm{Si}$ MAS NMR spectra of the representative samples clearly demonstrated that a large number of defect sites formed during the treatment caused the collapse of the framework (Fig. 7); Cal700-5h-1M-Amb-24h and Cal750-5h-1MAmb-24h showed higher proportions of $\mathrm{Q}^{3}$ and $\mathrm{Q}^{2}$ species than Cal800-24h-1M-Amb-24h. This tendency strongly suggests that the robustness against acid treatment was determined by the number of $\mathrm{Al}$ atoms and defect sites in the framework of the parent sample. Cal700-5h and Cal750-5h had 7.4 and 6.9 $\mathrm{Al}$ atoms (including $\mathrm{Q}^{3}$ sites) per unit cell (64 $\mathrm{T}$ atoms), respectively, which would be the defect sites after acid treatment. Notably, although the peak areas of $\mathrm{Q}^{4}(2 \mathrm{Al})$ and $\mathrm{Q}^{4}(1 \mathrm{Al})$ species included those of $\mathrm{Q}^{2}$ and $\mathrm{Q}^{3}$ species, respectively, the $\mathrm{Si} / \mathrm{Al}_{\mathrm{FW}}$ ratios were calculated with the proportions of $\mathrm{Q}^{2}$ and $\mathrm{Q}^{3}$ species included because these partially hydrolyzed $\mathrm{Q}^{2}$ and $\mathrm{Q}^{3}$ species are themselves defects and can also be considered as the cause of framework destruction. These findings present a method for modifying the OSDA-free Beta; the high-aluminum framework of the Beta zeolite can be converted into a high-silica one with the framework $\mathrm{Si} / \mathrm{Al}$ ratio higher than 12 by calcination of the $\mathrm{NH}_{4}$-form zeolite and subsequently, extra-framework and framework Al species can be removed by acids. The conventional Beta zeolites, synthesized with the TEA cation as an OSDA, have typical $\mathrm{Si} / \mathrm{Al}_{\mathrm{FW}}$ ratios around 12 and their framework $\mathrm{Al}$ atoms are easily removed by acid treatment with the

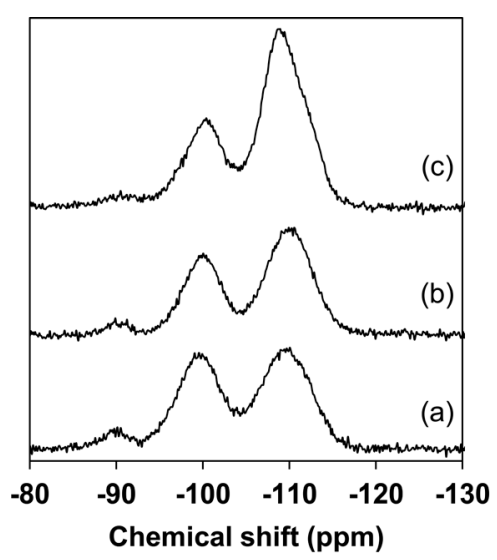

Fig. $7{ }^{29}$ Si MAS NMR spectra of calcined and acid-treated Beta(OF) zeolites: (a) Cal700-5h-1M-Amb-24h, (b) Cal750-5h-1M-Amb-24h, and (c) Cal800-24h-1M-Amb-24h. 
crystalline structure retained, ${ }^{43,49,50}$ fully consistent with the theory above.

Removal of $\mathrm{Al}$ atoms was further studied using Cal800-24h as the parent material. The $\mathrm{Al}$ contents were decreased from 50 to 204 by increasing the temperature, concentration of acid, and period of treatment. The X-ray diffraction intensities did not change significantly, indicating the preservation of the crystalline structure (Fig. 8). Fig. 9 shows the ${ }^{27} \mathrm{Al}$ MAS NMR spectra of Cal800-24h after acid treatment under various conditions. Cal800-24h-1M-Amb-24h showed a peak at 54 ppm with a small peak at 0 ppm. No peak was observed at 57 and $\sim 30 \mathrm{ppm}$ in the spectrum, indicating that the mild acid treatment mainly removed the extra-framework $\mathrm{Al}$ species and the framework Al species at the T3-T9 sites. Thereafter, the increased severity of the treatment led to the removal of framework tetrahedral $\mathrm{Al}$ species at the T1 and T2 sites, as shown in the decreased peak at $54 \mathrm{ppm}$. This preferential removal of specific Al species has been also observed in typical Beta zeolites synthesized with the TEA cation. ${ }^{43}$ The specific surface areas increased due to acid treatment (Table 3). This is probably because extra-framework Al species accumulated in the micropores were eliminated, increasing the pore volume accessible to nitrogen molecules. All the samples except for Cal800-24h-3M-Ref-2h had BET surface areas greater than $600 \mathrm{~m}^{2} \mathrm{~g}^{-1}$, reflecting their high crystallinity. Cal800-24h-3M-Ref-2h showed deviating characteristics as observed in the slightly low X-ray diffraction intensity and BET surface area, although the reasons for this behavior have not been clear.

The acid properties of these samples were characterized by $\mathrm{NH}_{3}$-TPD (Table 3 and Fig. S2 $\dagger$ ). The acid amount of

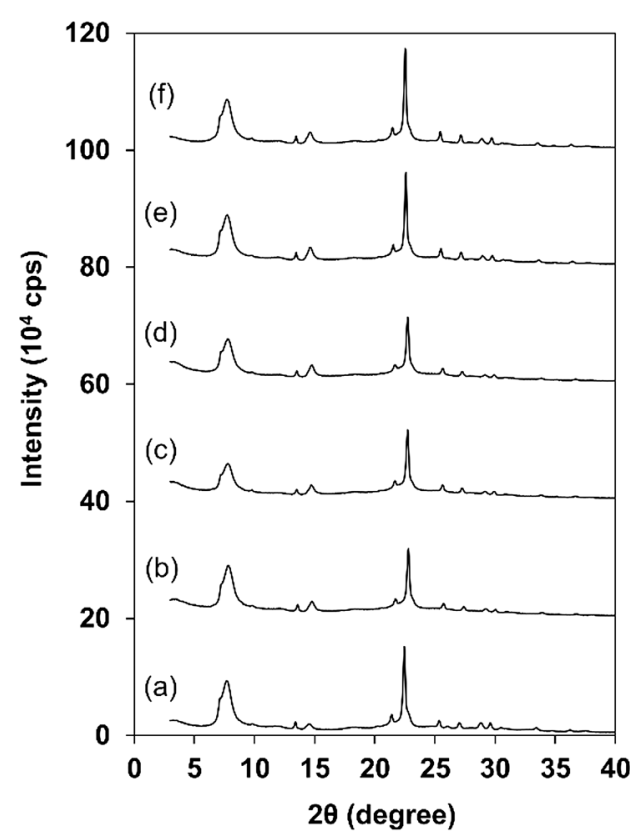

Fig. 8 XRD patterns of Cal800-24h derivatives acid-treated under different conditions: (a) Cal800-24h, (b) Cal800-24h-1M-Amb-24h, (c) Cal800-24h-1M-Ref-2h, (d) Cal800-24h-3M-Ref-2h, (e) Cal800-24h$6 M-$ Ref-2h, and (f) Cal800-24h-6M-Ref-24h.

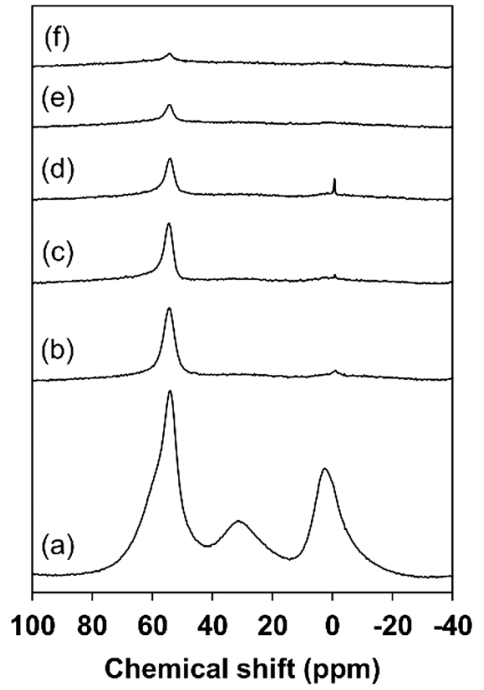

Fig. $9{ }^{27} \mathrm{Al}$ MAS NMR spectra of Cal800-24h derivatives acid-treated under different conditions: (a) Cal800-24h, (b) Cal800-24h-1M-Amb24h, (c) Cal800-24h-1M-Ref-2h, (d) Cal800-24h-3M-Ref-2h, (e) Cal800-24h-6M-Ref-2h, and (f) Cal800-24h-6M-Ref-24h.

Cal800-24h (ca. $0.896 \mathrm{mmol} \mathrm{g}^{-1}$ ) was much lower than the whole Al content calculated by ICP analysis, indicating that the extra-framework Al species did not act as acid sites. For the acid-treated samples, the acid amount monotonously decreased to $0.035 \mathrm{mmol} \mathrm{g}^{-1}$. Thus, high-silica Beta zeolites with controlled $\mathrm{Si} / \mathrm{Al}$ ratios and acid amounts were successfully prepared from OSDA-free Beta with high-aluminum composition through calcination at $800{ }^{\circ} \mathrm{C}$ and subsequent acid treatment.

\section{Methanol-to-olefin (MTO) reaction over Beta(OF) zeolites}

The catalytic performance of Cal800-24h and its derivatives was measured in MTO reactions. Firstly, the influence of the acid amount on the catalytic performance was investigated. The reaction runs were conducted at the feed rate (WHSV) of $6.4 \mathrm{~h}^{-1}$ with a methanol partial pressure of $50 \mathrm{kPa}$. The changes in the conversion of methanol and the product selectivity along with time-on-stream (TOS) are given in Fig. 10 and summarized in Table 4. Cal800-24h initially showed complete conversion of methanol at a TOS of $10 \mathrm{~min}$ with

Table 3 Composition, surface area and acid amount of Cal800-24h and its acid-treated derivatives

\begin{tabular}{lcll}
\hline Sample & $\mathrm{Si}^{2} \mathrm{Al}^{a}$ & $S_{\text {BET }^{b}}\left(\mathrm{~m}^{2} \mathrm{~g}^{-1}\right)$ & $\operatorname{Acid}^{c}\left(\mathrm{mmol} \mathrm{g}^{-1}\right)$ \\
\hline Cal800-24h & 4.5 & 559 & 0.896 \\
Cal800-24h-1M-Amb-24h & 50 & 602 & 0.212 \\
Cal800-24h-1M-Ref-2h & 80 & 664 & 0.097 \\
Cal800-24h-3M-Ref-2h & 92 & 580 & 0.069 \\
Cal800-24h-6M-Ref-2h & 112 & 635 & 0.066 \\
Cal800-24h-6M-Ref-24h & 204 & 624 & 0.035
\end{tabular}

${ }^{a}$ The whole Si/Al ratio analyzed by ICP. ${ }^{b}$ BET surface area calculated from $\mathrm{N}_{2}$ adsorption isotherms. ${ }^{c}$ The number of acid sites determined by $\mathrm{NH}_{3}$-TPD. 
(a)

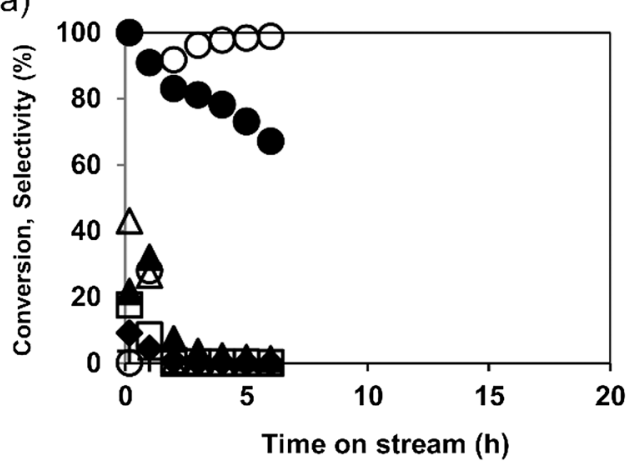

(c)

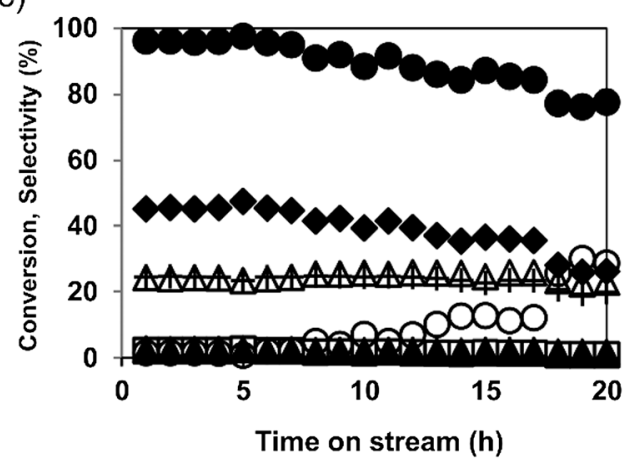

(b)

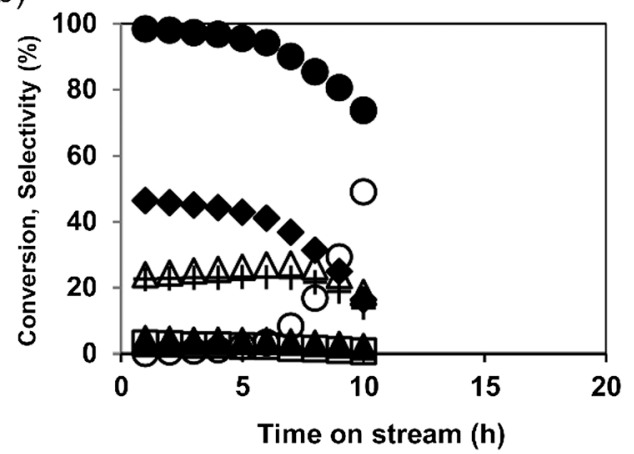

(d)

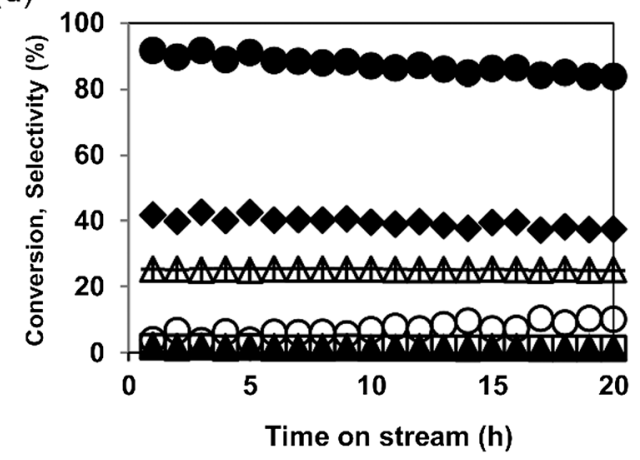

Fig. 10 Time course in MTO reactions over (a) Cal800-24h, (b) Cal800-24h-1M-Amb-24h, (c) Cal800-24h-1M-Ref-2h, and (d) Cal800-24h-6MRef-2h. $(\bullet)$ Conversion of methanol, and selectivities to $(0)$ DME, $(\square)$ ethene, $(\bullet)$ propene, $(\Delta)$ butenes, $(\Delta)$ light paraffins and $(+)>C_{5}$ products.

selectivities to light olefins (ethene, propene and butenes) of $30 \%$. It is noteworthy that light paraffins $\left(\mathrm{C}_{1}-\mathrm{C}_{4}\right)$ and heavy products were produced in relatively high selectivities probably because the hydride transfer reaction significantly proceeded. ${ }^{51}$ The selectivities to the light olefins suddenly decreased to $\sim 1 \%$ at $2 \mathrm{~h}$ when dimethyl ether (DME) was mainly produced in $\sim 90 \%$ selectivity. The very quick deactivation could be attributed to its high density of acid sites over which a large amount of coke accumulated. ${ }^{51,52}$ The lifetime was remarkably extended for the acid-treated catalysts with the high-silica composition. ${ }^{53}$ The product selectivity also improved for the acid-treated samples; the initial selectivities to the light olefins were around $70 \%$. Intriguingly, ethene was produced in low yield, while propene and butenes were produced in much higher yields. This is probably because aromatic hydrocarbon pools formed in the 12-MR pores such as penta- and hexamethylbenzene favor the formation of propene and butenes, while those in the 10-MR pores of ZSM-5 favor the formation of ethene and propene. ${ }^{54}$ This product selectivity is complementary to that of steam cracking of naphtha in which ethene is produced as the main light olefin product. ${ }^{31}$ Although ZSM-5 can be synthesized without the use of an OSDA such as the tetrapropylammonium (TPA) cation, OSDA-free ZSM-5 is highly resistant against acid

Table 4 MTO reactions over Cal800-24h and its acid-treated catalysts ${ }^{a}$

\begin{tabular}{|c|c|c|c|c|c|c|c|c|}
\hline $\begin{array}{l}\mathrm{Si} / \mathrm{Al} \\
\text { TOS }^{b}(\mathrm{~h})\end{array}$ & \multicolumn{2}{|l|}{4.6} & \multicolumn{2}{|l|}{50} & \multicolumn{2}{|l|}{80} & \multicolumn{2}{|l|}{112} \\
\hline Conversion (\%) & 100 & 83.0 & 98.3 & 90.0 & 96.1 & 91.5 & 91.7 & 83.7 \\
\hline \multicolumn{9}{|c|}{ Product selectivity (\%) } \\
\hline $\mathrm{DME}^{c}$ & 0 & 91.7 & 0 & 8.2 & 1.6 & 4.8 & 3.9 & 10.0 \\
\hline Butenes & 3.5 & 0 & 22.5 & 22.9 & 24.5 & 24.6 & 25.2 & 24.8 \\
\hline Light paraffins $^{d}$ & 21.5 & 7.2 & 4.4 & 3.4 & 2.5 & 2.2 & 2.2 & 1.5 \\
\hline$>\mathrm{C}_{5}$ & 43.0 & 0 & 23.7 & 27.1 & 24.2 & 25.3 & 25.2 & 25.1 \\
\hline
\end{tabular}

${ }^{a}$ Catalyst, $0.1 \mathrm{~g}$; WHSV $=6.4 \mathrm{~h}^{-1} ; P_{\mathrm{MeOH}}=50 \mathrm{kPa}\left(\right.$ He balance); $500{ }^{\circ} \mathrm{C} .{ }^{b}$ Time on stream. ${ }^{c}$ Dimethyl ether. ${ }^{d} \mathrm{C}_{1}-\mathrm{C}_{4}$ paraffins. 
Table 5 MTO reactions over high-silica Beta zeolite under different conditions $^{a}$

\begin{tabular}{|c|c|c|c|c|c|c|}
\hline WHSV $\left(h^{-1}\right)$ & 6.4 & & 3.2 & & 3.2 & \\
\hline$P_{\mathrm{MeOH}}(\mathrm{kPa})$ & 50 & & 50 & & 75 & \\
\hline $\operatorname{TOS}^{b}(\mathrm{~h})$ & 1 & 20 & 5 & 40 & 5 & 40 \\
\hline Conversion & 91.7 & 83.7 & 98.4 & 91.0 & 96.7 & 89.6 \\
\hline \multicolumn{7}{|c|}{ Product selectivity (\%) } \\
\hline $\mathrm{DME}^{c}$ & 3.9 & 10.0 & 0 & 3.8 & 0 & 3.9 \\
\hline Ethene & 1.7 & 1.3 & 2.3 & 1.5 & 2.1 & 1.5 \\
\hline Propene & 41.8 & 37.4 & 48.0 & 41.0 & 49.7 & 43.8 \\
\hline Butenes & 25.2 & 24.8 & 25.0 & 25.8 & 25.8 & 25.9 \\
\hline Light paraffins ${ }^{d}$ & 2.2 & 1.5 & 2.2 & 2.0 & 1.9 & 1.5 \\
\hline$>\mathrm{C}_{5}$ & 25.2 & 25.1 & 22.6 & 25.9 & 20.5 & 23.3 \\
\hline
\end{tabular}

${ }^{a}$ Cal800-24h-6M-Ref-2h, $0.1 \mathrm{~g} ; 500{ }^{\circ} \mathrm{C} .{ }^{b}$ Time on stream. ${ }^{c}$ Dimethyl ether. ${ }^{d} \mathrm{C}_{1}-\mathrm{C}_{4}$ paraffins.

treatments compared to ZSM-5 synthesized with the TPA cation and Beta. ${ }^{50,55}$ Thus, the unique physicochemical properties of the modified OSDA-free Beta with high-silica compositions are highly advantageous for the MTO reaction.

High-silica zeolite is favorable in terms of product selectivity and catalyst life, though the catalytic activity decreases as the number of acid sites decreases. ${ }^{53}$ Next, we optimized the reaction conditions by using Cal800-24h-6M-Ref-2h (Table 5). When the feed rate was decreased $\left(\mathrm{WHSV}=3.2 \mathrm{~h}^{-1}\right)$, the initial conversion of methanol increased to $98 \%$. The selectivities to the light olefins increased to $75 \%$ with the decrease in the selectivities to DME. The conversion of methanol was over $90 \%$ until $40 \mathrm{~h}$, when the selectivities to the light olefins decreased to $68 \%$. Although the total amount of methanol fed until $40 \mathrm{~h}$ at WHSV $=3.2 \mathrm{~h}^{-1}$ was equal to that until $20 \mathrm{~h}$ at WHSV $=6.4 \mathrm{~h}^{-1}$, both the total amount of methanol converted and the total yield of light olefins were higher for the operation at the lower feed rate. These results demonstrated that the efficiency in the MTO reaction is dependent on the feed rate ${ }^{56}$ and that the rate at WHSV $=3.2 \mathrm{~h}^{-1}$ well matches the activity of Cal800-24h-6M-Ref-2h. When the partial pressure of methanol was increased to $75 \mathrm{kPa}$ by decreasing the amount of helium carrier, the selectivities to the light olefins were slightly improved and the selectivities were kept over $70 \%$ at a TOS of $40 \mathrm{~h}$.

\section{Conclusions}

A facile method for tuning the Al content of OSDA-free Beta has been developed; the combination of calcination above $750{ }^{\circ} \mathrm{C}$ and acid treatment led to a decrease in the number of $\mathrm{Al}$ atoms in the framework with the * BEA structure retained. The degree of stabilization of the framework against acid treatment was quantitatively evaluated in terms of the framework Al content, successfully finding that the framework with the $\mathrm{Si} / \mathrm{Al}$ ratio higher than 12 can be treated with nitric acid with the crystal structure retained. Thus, the prepared Beta zeolites exhibited a much longer catalytic life in the MTO reaction compared to the parent high-aluminum OSDA-free Beta. Particularly for the Beta zeolite catalyst with the Si/Al ratio of 112 , the conversion of methanol was over $90 \%$ with the selectivity to light olefins over $70 \%$ throughout 40 hours on stream at WHSV $=3.2 \mathrm{~h}^{-1}$ and $P_{\mathrm{MeOH}}=75 \mathrm{kPa}$. Our findings will contribute to the control of the acidic properties of Al-rich zeolites, and would broaden the catalytic applications of OSDA-free Beta.

\section{Acknowledgements}

The present work was performed under the framework of the INCOE (International Network of Centers of Excellence) project coordinated by BASF SE.

\section{Notes and references}

1 M. E. Davis and R. F. Lobo, Chem. Mater., 1992, 4, 756.

2 C. S. Cundy and P. A. Cox, Chem. Rev., 2003, 103, 663.

3 M. Moliner, F. Rey and A. Corma, Angew. Chem., Int. Ed., 2013, 52, 2.

4 X. Meng and F.-S. Xiao, Chem. Rev., 2014, 114, 1521.

5 K. Iyoki, K. Itabashi and T. Okubo, Microporous Mesoporous Mater., 2014, 189, 22.

6 B. Xie, J. Song, L. Ren, Y. Ji, J. Li and F.-S. Xiao, Chem. Mater., 2008, 20, 4533.

7 E. Blomsma, J. A. Martens and P. A. Jacobs, J. Catal., 1997, 165, 24.

8 M. A. Camblor, A. Corma, A. Martínez, V. Martínez-Soria and S. Valencia, J. Catal., 1998, 179, 537.

9 H. K. Heinichen and W. F. Hölderich, J. Catal., 1999, 185, 408.

10 U. Freese, F. Heinrich and F. Roessner, Catal. Today, 1999, 49, 237.

11 G. Sartori and R. Maggi, Chem. Rev., 2006, 106, 1077.

12 J. Wennerberg, F. Ek, A. Hansson and T. Frejd, J. Org. Chem., 1999, 64, 54.

13 L. Eklund, A. Axelsson, A. Nordahl and R. Carlson, Acta Chem. Scand., 1993, 47, 581.

14 E. J. Creyghton, S. D. Ganeshie, R. S. Downing and H. van Bekkum, J. Mol. Catal. A: Chem., 1997, 115, 457.

15 B. Coq, M. Mauvezin, G. Delahay, J.-B. Butet and S. Kieger, Appl. Catal., B, 2000, 27, 193.

16 J. Pérez-Ramírez, J. C. Groen, A. Brückner, M. S. Kumar, U. Bentrup, M. N. Debbagh and L. A. Villaescusa, J. Catal., 2005, 232, 318.

17 R. L. Wadlinger, G. T. Kerr and E. J. Rosinski, US Pat., 3308069, 1967.

18 R. B. Borade and A. Clearfield, Microporous Mater., 1996, 5, 289.

19 P. R. H. P. Rao and M. Matsukata, Chem. Commun., 1996, 1441.

20 M. A. Camblor, A. Corma and S. Valencia, J. Mater. Chem., 1998, 8, 2137.

21 G. Majano, L. Delmotte, V. Valtchev and S. Mintova, Chem. Mater., 2009, 21, 4184.

22 Y. Kamimura, W. Chaikittisilp, K. Itabashi, A. Shimojima and T. Okubo, Chem. - Asian J., 2010, 5, 2182. 
23 Y. Kamimura, S. Tanahashi, K. Itabashi, A. Sugawara, T. Wakihara, A. Shimojima and T. Okubo, J. Phys. Chem. C, 2011, 115, 744.

24 H. Zhang, B. Xie, X. Meng, U. Müller, B. Yilmaz, M. Feyen, S. Maurer, H. Gies, T. Tatsumi, X. Bao, W. Zhang, D. de Vos and F.-S. Xiao, Microporous Mesoporous Mater., 2013, 180, 123.

25 M. Ogura, K. Itabashi, J. Dedecek, T. Onkawa, Y. Shimada, K. Kawakami, K. Onodera, S. Nakamura and T. Okubo, J. Catal., 2014, 315, 1.

26 P. Sazama, B. Wichterlová, Š. Sklenák, V. I. Parvulescu, N. Candu, G. Sádovská, J. Dědeček, P. Klein, V. Pashkova and P. Štastný, J. Catal., 2014, 318, 22.

27 B. Xie, H. Zhang, C. Yang, S. Liu, L. Ren, L. Zhang, X. Meng, B. Yilmaz, U. Müller and F.-S. Xiao, Chem. Commun., 2011, 47, 3945.

28 B. Yilmaz, U. Müller, M. Feyen, S. Maurer, H. Zhang, X. Meng, F.-S. Xiao, X. Bao, W. Zhang, H. Imai, T. Yokoi, T. Tatsumi, H. Gies, T. de Baerdemaeker and D. de Vos, Catal. Sci. Technol., 2013, 3, 2580.

29 T. de Baerdemaeker, B. Yilmaz, U. Muller, M. Feyen, F.-S. Xiao, W. Zhang, T. Tatsumi, H. Gies, X. Bao and D. de Vos, J. Catal., 2013, 308, 73.

30 Y. Kubota, K. Itabashi, S. Inagaki, Y. Nishita, R. Komatsu, Y. Tsuboi, S. Shinoda and T. Okubo, Chem. Mater., 2014, 26, 1250.

31 J. S. Plotkin, Catal. Today, 2005, 106, 10.

32 B. Yilmaz and U. Müller, Top. Catal., 2009, 52, 888.

33 M. Stöcker, Microporous Mesoporous Mater., 1999, 29, 3.

34 U. Olsbye, S. Svelle, M. Bjørgen, P. Beato, T. V. W. Janssens, F. Joensen, S. Bordiga and K. P. Lillerud, Angew. Chem., Int. Ed., 2012, 51, 5810.

35 P. Tian, Y. Wei, M. Ye and Z. Liu, ACS Catal., 2015, 5, 1922.

36 J. Q. Chen, A. Bozzano, B. Glover, T. Fuglerud and S. Kvisle, Catal. Today, 2005, 106, 103.

37 J. Higgins, R. B. LaPierre, J. Schlenker, A. Rohrman, J. Wood, G. Kerr and W. Rohrbaugh, Zeolites, 1988, 8, 446.
38 J. Newsam, M. Treacy, W. Koetsier and C. de Gruyter, Proc. R. Soc. London, Ser. A, 1988, 420, 375.

39 R. C. Boggs, D. G. Howard, J. V. Smith and G. L. Klein, Am. Mineral., 1993, 78, 822.

40 G. Valerio, A. Goursot, R. Vetrivel, O. Malkina, V. Malkin and D. R. Salahub, J. Am. Chem. Soc., 1998, 120, 11426.

41 J. Stelzer, M. Paulus, M. Hunger and J. Weitkamp, Microporous Mesoporous Mater., 1998, 22, 1.

42 J. A. van Bokhoven, D. C. Koningsberger, P. Kunkeler, H. van Bekkum and A. P. M. Kentgens, J. Am. Chem. Soc., 2000, 122, 12842.

43 A. Omegna, M. Vasic, J. Anton van Bokhoven, G. Pirngruber and R. Prins, Phys. Chem. Chem. Phys., 2004, 6, 447.

44 S. Li, A. Zheng, Y. Su, H. Fang, W. Shen, Z. Yu, L. Chen and F. Deng, Phys. Chem. Chem. Phys., 2010, 12, 3895.

45 Z. Yu, A. Zheng, Q. Wang, L. Chen, J. Xu, J.-P. Amoureux and F. Deng, Angew. Chem., Int. Ed., 2010, 49, 8657.

46 G. H. Kuehl and H. K. C. Timken, Microporous Mesoporous Mater., 2000, 35-36, 521.

47 S. M. Maier, A. Jentys and J. A. Lercher, J. Phys. Chem. C, 2011, 115, 8005.

48 R. Otomo, T. Yokoi, J. N. Kondo and T. Tatsumi, Appl. Catal., A, 2014, 470, 318.

49 E. B. Lami, F. Fajula, D. Anglerot and T. Des Courieres, Microporous Mater., 1993, 1, 237.

50 M. Müller, G. Harvey and R. Prins, Microporous Mesoporous Mater., 2000, 34, 135.

51 D. M. Bibby, R. F. Howe and G. D. McLellan, Appl. Catal., A, 1992, 93, 1-34.

52 M. Bjørgen, U. Olsbye and S. Kolboe, J. Catal., 2003, 215, 30.

53 M. Bjørgen and S. Kolboe, Appl. Catal., A, 2002, 225, 285.

54 M. Bjørgen, F. Joensen, K.-P. Lillerud, U. Olsbye and S. Svelle, Catal. Today, 2009, 142, 90.

55 S. Inagaki, S. Shinoda, Y. Kaneko, K. Takechi, R. Komatsu, Y. Tsuboi, H. Yamazaki, J. N. Kondo and Y. Kubota, ACS Catal., 2013, 3, 74.

$56 \emptyset$. Mikkelsen and S. Kolboe, Microporous Mesoporous Mater., 1999, 29, 173. 